\title{
Multiple deficits in the retention of an appetitively motivated behavior across a $24-\mathrm{h}$ period in rats
}

\author{
JAMES P. HUNSICKER and ROGER L. MELLGREN \\ University of Oklahoma, Norman, Oklahoma 73019
}

\begin{abstract}
Recent investigations have found a multiphasic retention function associated with avoidance training (e.g., Holloway \& Wansley, 1973a, b). The present experiment was done to determine if a similar retention function also describes appetitively motivated behavior. Rats were allowed access to preferred solution in the shock compartment of a passive avoidance apparatus. Then either $.25 \mathrm{~h}$ after the appetitive preexposure or at successive $3-\mathrm{h}$ intervals up to $24 \mathrm{~h}$, the rats were administered one-trial passive avoidance training consisting of a strong shock presented in the shock compartment. The retention of the appetitive preexposure was determined by its effect on performance of the passive avoidance task as measured $24 \mathrm{~h}$ after the shock trial. The results demonstrated that the retention function associated with the appetitive preexposure was phasic with an alternation between high and low retention every $12 \mathrm{~h}$. Specifically, retention was higher after the .25-, 9-, 12-, and 24-h intervals than after 3-, 6-, 15-, and 18-h intervals. These results are consistent with prior research on the retention of avoidance training.
\end{abstract}

Kamin (1957) reported that retention of an incompletely learned shuttlebox avoidance response by rats was a U-shaped function of time since original training ("Kamin effect"). He measured retention by the number of avoidance responses in a relearning phase and found that it declined to a minimum after $1 \mathrm{~h}$, then increased across the next 19 days. Holloway and Wansley $(1973 \mathrm{a}, \mathrm{b})$ measured retention at several intervals during the $24 \mathrm{~h}$ following training on either one-trial passive avoidance or multitrial one-way active avoidance. They reported that rats had higher retention scores at $15 \mathrm{~min}$ and at successive multiples of $12 \mathrm{~h}$ after training than at $6 \mathrm{~h}$ and at successive multiples of $12 \mathrm{~h}$ from the 6-h interval. These data indicate a multiphasic retention function for avoidance responding.

Attempts to determine the retention function following appetitive training have produced conflicting results. Some investigators have found no retention deficits in the $24 \mathrm{~h}$ following training (Gabriel, 1968; Hablitz \& Braud, 1972); others have reported a single retention deficit (Caul, Barrett, Thune, \& Osborne, 1974; Tribhowan, Rucker, and McDiarmid, 1971). Unfortunately, none of these studies includes a systematic range of training-testing intervals during the $24 \mathrm{~h}$ following training, as in Holloway and Wansley's aversive conditioning experiments. In a recent experiment, however, Wansley and Holloway (1975) varied the training-testing

Based on a Master's thesis prepared by the first author under the direction of the second author which was submitted to the Psychology Department, University of Oklahoma, 1973. Reprint requests should be addressed to Roger L. Mellgren, Department of Psychology, University of Oklahoma, Norman, Oklahoma 73019. interval during the $24 \mathrm{~h}$ following training, and they obtained a phasic retention function similar to that found in their aversive paradigms (Holloway \& Wansley, 1973a, b). They deprived rats of water for $24 \mathrm{~h}$ prior to one-trial appetitive maze training in which 5-min access to water was the reinforcer and tested for retention at intervals of $0.25,1,6,12,18$, or $24 \mathrm{~h}$. Retention at $0.25,1,12$, and $24 \mathrm{~h}$ was greater than at 6 and $18 \mathrm{~h}$.

Testing for appetitive retention across different time intervals poses two problems. First, the retention test must be sensitive enough to pick up differences when exposure to the appetitive event is brief, since either lengthy exposure or multiple trials make it difficult to pinpoint a specific time of occurrence of the appetitive event. Retention deficits have been reported most often when the learning period is brief (e.g., one-trial passive avoidance). Second, motivational factors (deprivation time) must be controlled across the various intervals to prevent an interaction with possible retention fluctuations. Wansley and Holloway (1975) resolved the first problem but possibly not the second. They allowed all groups to have 10 -min access to water $1 \mathrm{~h}$ prior to training, and $1 \mathrm{~h}$ prior to testing gave another 10 -min access to water for all groups except those tested at 0.25 and $1 \mathrm{~h}$. This procedure was designed to equate the degree of deprivation across groups, although the possibility of differing deprivation levels exists because the rats in the various groups were deprived to differing degrees at the time of the 10 -min free access period, in addition to the obvious problems for the 0.25 - and 1-h conditions. The present experiment attempted to overcome these two problems by employing a different procedure to study the appetitive retention function. 
Rats were given access to a preferred solution, milk with sugar added, in the shock compartment of a passive avoidance apparatus. Following one of eight intervals, the subjects received one-trial passive avoidance acquisition, and $24 \mathrm{~h}$ later were tested for the degree of avoidance. Using the same procedure, but only a 6-min interval between preexposure and passive avoidance training, Mellgren, Hunsicker, and Dyck (1975) found that the appetitive preexposure significantly reduced the amount of passive avoidance behavior when compared to rats either not preexposed or rats given exploratory preexposure to the shock compartment. The interval between preexposure and passive avoidance acquisition and between preexposure and testing were the only conditions which varied between groups in the present experiment. Thus any differences between groups must be a function of differential retention of the appetitive preexposure either on the acquisition training trial or the testing trial. Either process would reflect the retention function for an appetitive event. Good retention of the appetitive preexposure should result in a short step-through latency during testing for passive avoidance, and poor preexposure retention should result in a long step-through latency during testing. The influence of circadian variables on retention was evaluated by administering preexposure at one of two time periods spaced $6 \mathrm{~h}$ apart. This procedure is sensitive, and since the appetitive preexposure consists of the presentation of a substance which does not require deprivation, motivational factors should not confound the preexposure retention function.

\section{METHOD}

\section{Subjects}

The subjects were 72 male albino rats of the Sprague-Dawley strain between 250 and 300 days old. All subjects were individually caged in a temperature and humidity controlled environment with continuous illumination and ad-lib food and water.

\begin{abstract}
Apparatus
All preexposure, training, and testing took place in a passive avoidance apparatus which was $90 \mathrm{~cm}$ long, $14 \mathrm{~cm}$ wide, and $30 \mathrm{~cm}$ deep. The apparatus was divided into two equal-size compartments (one black, one white) by a clear Plexiglas guillotine door. The apparatus had a hardware cloth top and grid floor consisting of parallel aluminum bars through which a scrambled shock of $0.8 \mathrm{~mA}$ could be administered. Table sugar and homogenized milk were combined to yield a solution consisting of approximately $30 \%$ sugar by weight. The sugared milk solution was placed in a jar lid, $3 \mathrm{~cm}$ in diameter, and attached to the rear wall of the black compartment only during preexposure.
\end{abstract}

\section{Procedure}

The rats were randomly assigned to one of eight independent groups. The eight groups were designated by their preexposurepassive avoidance acquisition intervals (PPIs), which were $15 \mathrm{~min}$ and $3,6,9,12,15,18$, and $24 \mathrm{~h}$. Five subjects in each PPI were preexposed at one time $(0800-1100 \mathrm{~h})$, while the remaining four subjects per treatment were preexposed $6 \mathrm{~h}$ later $(1400-1700 \mathrm{~h})$. Thus, the design of this experiment was a 2 (preexposure time) by 8 (PPI) factorial.

The order in which the subjects in the different PPIs were preexposed was counterbalanced throughout both preexposure periods. During preexposure, each subject was placed in the white compartment of the apparatus and permitted access to the black compartment, where approximately $20 \mathrm{cc}$ of sugared milk was located. After entering the black side, the guillotine door was lowered and the subject was allowed $5 \mathrm{~min}$ access to the sugared milk solution before being returned to its home cage.

In passive avoidance acquisition, each subject was placed in the safe compartment (white side) facing the wall opposite the door to the shock compartment (black side). When the rat oriented toward the shock compartment, the door was raised and the rat's step-through latency was recorded. Five seconds after the subject entered the shock compartment, the .8-mA shock was delivered for $5 \mathrm{sec}$. The rat was then returned to its home cage $5 \mathrm{sec}$ after shock offset. Acquisition training consisted of one trial. The acquisition-testing interval was $24 \mathrm{~h}$ across all treatment groups.

During the testing session, the subjects were placed in the safe compartment, as in acquisition with the exception that no shock was used. Testing lasted for $15 \mathrm{~min}$, during which the rat's step-through latency was measured. Any rat failing to enter the shock compartment within $15 \mathrm{~min}$ was removed from the apparatus and a testing step-through latency of $900 \mathrm{sec}$ was recorded. The criterion for exiting from the safe compartment was that the subject had its back paws on the second bar inside the shock compartment.

\section{RESULTS}

A 2 by 8 factorial ANOVA on the testing stepthrough latencies yielded a reliable difference for the PPI main effect, $F(7,56)=7.35$, $p<.01$, but nonreliable differences between the two preexposure periods and the PPI by Preexposure Period interaction. Figure 1 shows the mean testing step-through latencies for the eight PPI treatment collapsed across the two preexposure periods. The retention curve is

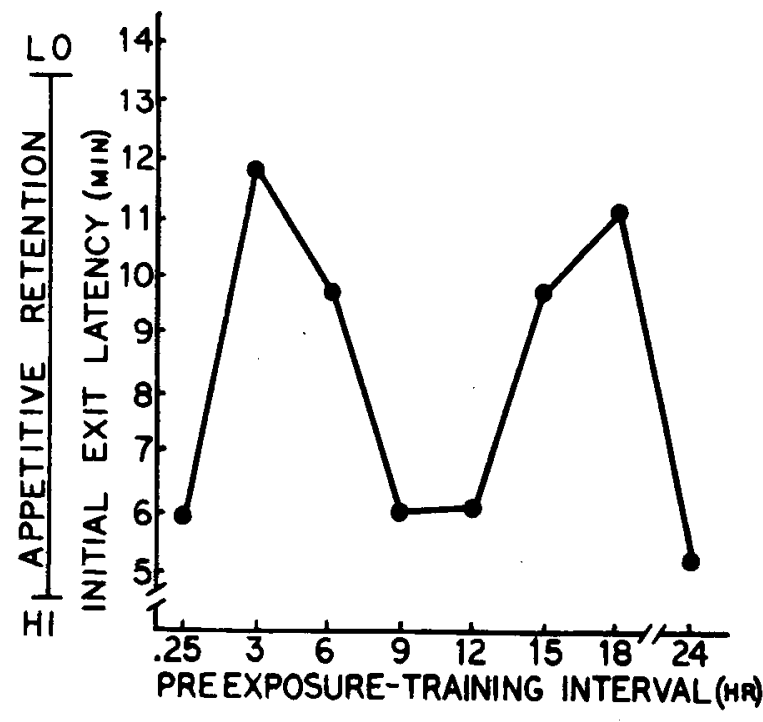

Figure 1. Mean initial exit latencies for the eight preexposuretraining interval treatments collapsed across the two preexposure periods. 
Table 1

Tukey's Pairwise Comparisons

\begin{tabular}{|c|c|c|c|c|c|c|c|c|}
\hline & & & & ting-IE & (min) & & & \\
\hline & $.25 \mathrm{~h}$ & $3 \mathrm{~h}$ & $6 \mathrm{~h}$ & $9 \mathrm{~h}$ & $12 \mathrm{~h}$ & $15 \mathrm{~h}$ & $18 \mathrm{~h}$ & $24 \mathrm{~h}$ \\
\hline & 6.0 & 11.4 & 9.7 & 5.8 & 6.1 & 9.9 & 11.4 & 5.5 \\
\hline 6.0 & & $5.4^{* *}$ & 3.7 & .2 & .1 & $3.9^{*}$ & $5.4^{* *}$ & .5 \\
\hline 11.4 & & & 1.7 & $5.6 * *$ & $5.3^{* *}$ & 1.5 & .0 & $5.9^{* *}$ \\
\hline 9.7 & & & & $3.9 *$ & 3.6 & .2 & 1.7 & $4.2^{*}$ \\
\hline 5.8 & & & & & .3 & $4.1^{*}$ & $5.6^{* *}$ & .3 \\
\hline 6.1 & & & & & & 3.8 & $5.3^{* *}$ & .6 \\
\hline 9.9 & & & & & & & 1.5 & $4.4^{*}$ \\
\hline 11.4 & & & & & & & & $5.9 * *$ \\
\hline 5.5 & & & & & & & & \\
\hline & & & & & & & & \\
\hline
\end{tabular}

phasic (retention of the appetitive preexposure is inversely related to step-through latency) with performance being lower in the 3-, 6-, 15-, and 18-h treatments than the 15-min, 9-, 12-, and 24-h treatments. Tukey's individual pairwise comparisons confirmed these effects except that the 6-h PPI was significantly different only from the 9 and $24 \mathrm{~h}$ PPIs (see Table 1).

The analysis of the training step-through latency produced reliable differences for both main effects and the interaction. The lack of reliable differences on this measure was probably due to a kind of ceiling effect, since all subjects entered the shock compartment at the start of passive avoidance acquisition in under $3 \mathrm{sec}$.

\section{DISCUSSION}

The results of this experiment demonstrate that, under the present conditions, the retention function associated with an appetitive event is phasic. The symmetry of the 6-, and 15-h groups on decline and incline, respectively, indicates that whatever underlying process(es) is occurring has a symmetrical function, not only at best and poorest retention intervals, but also at intermediate retention levels. Since the time of preexposure variable did not yield reliable differences for any of the dependent variables, timeof-day variables cannot account for the fluctuations in retention.

The present retention function is very similar to that reported when the interval between avoidance training and testing is varied (Holloway \& Wansley, 1973a, b). The present results also are consistent with the earlier findings of Wansley and Holloway (1975). Ignoring the results of the 3-, 9-, and 15-h intervals in the present study which were not included in their study, the pattern of these two appetitive retention functions is very similar. We did not manipulate deprivation, making it unlikely that the deprivation confound discussed earlier distorted the retention pattern present in the Wansley and Holloway study. The results of another study (Tribhowan, Rucker, \& McDiarmid, 1971) which demonstrated poorer retention of an appetitive task at a 4-h interval than at 15 -min or 8- or 24-h intervals also agree with the present findings. This deficit at the 4-h interval roughly corresponds to the deficit found at the 3-h interval when compared to the $0.25-, 9-$, and $24-\mathrm{h}$ intervals in the present experiment.

Since the multiple retention deficits associated with an appetitive event are similar to those found with an aversive event, the process(es) which underlies the fluctuations may be the same. This implies a general underlying process which is not directly due to either the aversive or appetitive nature of the task. Holloway and Wansley $(1973 a, b)$ suggested a statedependent or stimulus generalization hypothesis in which the state of the organism during training experience becomes an essential part of the conditioning and shifts away from the state influence retention performance via the decreased availability of relevant cues. They hypothesize that the physiological process or rhythm underlying that statedependent retention had a 12 -h periodicity. The hypothesized underlying biological rhythmic process(es) is unknown at this time.

\section{REFERENCES}

Caul, W. F., Barrett, R. J., Thune, G. E., \& Osborne, G. L. Avoidance decrement as a function of training-test interval: Single cycle or multiphasic? Behavioral Biology, 1974, 11, 409-414.

GABRIEL, M. Effects of intersession delay and training level on avoidance extinction and intertrial behavior. Journal of Comparative and Physiological Psychology, 1968, 66, 412-416.

Hablitz, J. J., \& Braud, W. G. Adrenaline, sodium amobarbital, and the Kamin effect in albino rats. Leaming and Motivation, 1972, 3, 151-158.

Holloway, F. A., \& Wansley, R. Multiphasic retention deficits at periodic intervals after passive avoidance learning. Science, 1973, 180, 208-210. (a)

Holloway, F. A., \& Wansley, R. Multiple retention deficits at periodic intervals after active and passive avoidance learning. Behavional Biology, 1973, 9, 1-14. (b)

KAMIN, L. J. Retention of an incompletely learned avoidance response. Joumal of Comparati'e and Physiological Psychology, $1957,50,457-460$.

Mellgren, R. L., Hunsicker, J. P., \& Dyck, D. G. Conditions of preexposure and passive avoidance behavior. Animal Leaming and Behavior, 1975, 3, 147-154.

Tribhowan, T., Rucker, W. B., \& McDiarmid, C. G. Demonstration of the Kamin like effect after appetitive training. Psychonomic Science, 1971, 23, 41-42.

Wansley, R. A., \& Holloway, F. A. Multiple retention deficits following one-trial appetitive training. Behavior Biology. 1975. 14, 1-15.

(Received for publication December 30, 1975; revision accepted September 19, 1976.) 